\title{
A study of the use of Twitter by students for lecture engagement and discussion
}

\begin{abstract}
Research indicates that student engagement with lectures, and participation in discussion and debate, greatly improve their learning and experience of University. The nature of some lectures means they can lack opportunities for interaction and active learning. For this reason it can be difficult for some students, especially students new to University, to fully engage in lectures, and interact with their peers. This study attempts to use Twitter as a means of increasing these opportunities for interaction and engagement for students, especially those who may lack the confidence to engage traditionally. As a first step, the study analyses the use of Audience Response Systems to understand the role technology can play in providing opportunities for interaction. Following this, a review of experiments conducted using Twitter is carried out. While there is a dearth of research in this area, these cases provide some valuable insights into the use of this technology and its integration into education. In the methodology section, the process of using Twitter in lectures is explained, along with some of the challenges and obstacles faced. Findings presented indicate that while adoption of Twitter was low, the platform provides engagement opportunities for timid members of the group, while having a generally positive impact on engagement and discussion for the group as a whole. Finally, emerging uses of the Twitter platform are examined, allowing the reader glimpse possibilities for future integration.
\end{abstract}

Keywords: Twitter, Audience Response Systems, interaction, engagement, discussion, technology, social media

\section{Introduction and context}

Entering a lecture hall for the first time, can be a potentially daunting experience for students, who have often come from smaller groups, to much larger, more diverse groups of people. This environment can prove difficult for students to adapt to, and very often they are shy and feel intimidated in the lecture setting. This can lead to a lack of interaction, especially in the early stages of college life, and lectures may become overpowered by the dominant few voices in the room (Moss \& Crowley, 2011). However, a number of recent studies indicate that students still prefer attending lectures over available online approaches. Students appear to value the learning achieved, structure provided, and enjoy the live aspects to lectures which cannot be replicated outside lecture halls. It is evident that the social interaction between peers and faculty is an important aspect of the success of these lectures (Gysbers et al, 2011; McElroy \& Blount, 2006; von Konsky et al, 2009). Moore (1989), Volery (2001), and Meyer (2002) all seem to agree that the quality of student learning is directly impacted by their interaction with fellow students, and their interaction with faculty and lecturing staff. The level of interaction in lectures is not ubiquitous, with some authors diagnosing lectures as weak links in University teaching (Blight, 1998; Duncan, 2005), due to their lack of interactivity and active learning methodologies (Draper \& Brown, 2004). As a result, many lecturers are using technology to achieve active and discovery based learning environments, allowing students to become involved in the learning process, and share experiences and opinions with faculty and peers (Morales, 2011; Chickering \& Ehrmann, 1996; Tamim et al, 2011; Farren, 2008; Crotty, 2011).

Audience Response Systems (ARS) are a technology that is commonly used to bridge the gap between the passive, disengaged content transmission model, where the lecturer delivers information and the student simply receives, to a more interactive and student centred model, where students are engaged in the learning process (Laurillard, 2002). ARS are handheld devices 
which are employed by faculty with the purpose of increasing student interaction. Prior to the delivery of course information during a lecture, related questions are prepared using specialised software which links to the handheld units. Students are then given the opportunity to answer these questions at certain prescribed times during the lecture. In order to answer a question, students must press the corresponding button on their handheld device. As this happens, the specialised software collates student button presses and displays the overall results for the entire class to see. Participation is generally anonymous and limited to button press answers to true/false, yes/no, and multiple choice questions. While their uses can vary to a certain degree, ARS are generally used during lectures to check understanding and initiate discussions (Simpson \& Oliver 2007).

A number of studies into the use of ARS in lectures suggest that ARS increase student engagement. The competitive nature of the 'quiz like' functions seems to appeal to students who enjoy seeing their responses compared in a 'who wants to be a millionaire' fashion (Abate et al, 2011). The relative ease of engagement experienced by having a personal handset and contributing with the press of a button, seems to facilitate participation by a far greater number of students, tackling the problem of lectures being dominated by the outspoken members of the class (Moss \& Crowley, 2011). However, the lasting impact on engagement outside of these 'quiz like' scenarios is still a matter for debate. It has been shown that students embrace using the technology in a manner that encourages processing the information being presented and discussed, and then 'speak out' to answer questions on it (Draper \& Brown, 2004). However, a recent study shows that attempts at follow up discussion and engagement can be futile (Morales, 2011). Morales (2011) found that outside of these questions and answer style interludes, students contributed little in the way of their own experiences and opinions, and often discussion on topics fell very flat. While this kind of question and answer interaction is an important step towards student engagement, the lack of contributions and discussion may make it difficult for lecturing staff to measure students real understanding of concepts. Perhaps more importantly, a lack of contextual discourse can limit the ability of students to measure their own learning, given that explanation and elaboration may not be offered. It is possible that while multiple choice questions increase engagement and participation, there is scope to use a tool that gathers student ideas, experiences, and opinions, and in doing so, facilitates a higher level of engagement and interaction (Moss \& Crowley, 2011).

The use of Twitter in education is less common; however it is emerging as a possible tool to increase the levels of interaction and discussion during lectures. Twitter (http://www.twitter.com) is real-time networking platform through which users communicate and share information of interest via 'small bursts' of information called 'tweets'. Each tweet is a short update $(\leq 140$ characters) containing user comments, musings or questions. Networks are established by 'following' or creating friends with similar interests. Unlike many other social platforms, updates are possible via the internet, Smartphone application, or SMS; making it one of the more versatile platforms available. Twitter has experienced enormous growth since its launch in 2006, with a variety of users taking advantage of its fast communication and information gathering. Current uses include daily chatter, conversation, information sharing and news reporting (Educause, 2007). While there is a dearth of research in the area, a small number of emerging studies on the use of the platform in education, suggests that it could also be used in this context to facilitate a more free flowing style of interaction.

Educause (2007) argue that the versatility of the Twitter platform enables its use in most educational settings. Due to its social design, the platform may promote student engagement in lectures by allowing free-flowing, two-way communication. In contrast to the fixed 'quiz time' offered by ARS, this facilitation of conversation throughout lectures may enable students to contribute more freely to discussion. Rankin's (2009) Twitter experiment seems to uphold this view, finding that students value using the platform as a means of communicating during lectures. Findings show that Twitter provided students with an outlet to express their views and opinions, and resulted in participation by students who are normally intimidated by speaking out in front of 
peers. This view was supported by Young (2009a), who found that using Twitter not only kept lectures fresh, but also that students lauded the ability to have their comments heard, without speaking out during class. By facilitation this conversation between lecturers and students, the platform may allow the integration of lecture content with students existing experience and social context, which can result in important academic and psychological development (Junco et al, 2011). In addition to this learning value, Hesmondhalgh (2011) suggests that through these shared interactions, student awareness of peer opinion and experience can increase, leading to the development of a sense of community. This sense of community seems to erode or remove perceived communication barriers, leading to superior levels of engagement and discussion (Thompson, 2007; Beldarrain, 2007), which provides students with the facility to construct and enhance each other's ideas in a group learning environment (Ebner et al, 2010). It appears that Twitter's social design and ability to facilitate two-way communication during lectures, may give lecturers the ability to draw out background information, feedback, and critical issues from students and in doing so, add to the levels of interaction offered by ARS.

The significance of engagement and discussion in lectures is prominent in many educational theories, featuring these attributes as pillars of their construction. For example; Bruner's (1967) discovery learning model posits that student learning is inquiry-based and constructive. Learning takes place in situations where students can draw upon past experiences and existing knowledge to bring together new facts and relationships, promoting active engagement and a tailored learning experience for the student. Vygotsky's (1978) social development theory emphasises learning contexts where students play an active role in their learning, instead of simply 'receiving' information. This form of learning environment allows students to construct shared meaning and play an active part in the development of their learning. Research indicates that the adoption of these learning principles in University could yield positive results. Engagement in the learning process and interaction with faculty and peers is understood to directly impact student learning, showing that those who are engaged in the learning process are more likely to learn (Crouch \& Mazur, 2001; Feden, 1994). Steinert \& Snell (1999) assert that this increased level of learning can be attributed to the arousal of student attention, promotion of higher order thinking and problem solving skills, which are caused by engagement and interaction in lectures. Bates et al (2006) also examined the effects of discussion and peer engagement on the learning process. While agreeing that it promotes higher levels of cognitive processing, they also found that this kind of interaction allows students to conduct their own formative assessment, throughout the duration of a course.

Technology is being used in a number of ways to increase student engagement in lectures. ARS are being used to promote student interaction by encouraging them to answer questions and engage in cognitive processes. While there is general agreement in the value of this kind of interaction, the lack of facilities for sharing of student experiences, opinions and concerns, exposes areas for possible improvement. Some studies have suggested that Twitter has the potential to go beyond multiple choice questions and create a social learning environment where ideas and experiences are shared with peers and lecturers in a fluid manner. However, few studies examine how this 'conversation' can allow students to link their experiences, opinion and concerns to lecture content. Also, qualitative studies into students' perceptions of the platform, its impact on class engagement, and its future uses, are not readily available. As such, this paper aims to add to the discussion in this field in the following ways. Firstly, due to the lack of research available on the use of Twitter in educational settings, and in lecture halls in particular, the study aims to provide further data on its implementation and impact. Second, the study will examine student adoption of Twitter as a means of engaging in lectures, focussing on students' willingness to use the platform, and the reasons for adoption or lack of adoption. The study will also add to the debate by examining the content of interactions using Twitter during lectures, providing some insight into its potential for drawing out student experiences and contexts. Also examined is the effect of Twitter on lecture engagement and discussion, paying particular attention to its impact on participation, and development of class community. Finally, the paper will examine students' perception for 
alternative and possible future uses for Twitter in academic settings. By approaching these topics, the study may provide useful information for other lecturers and/or academic staff looking to use Twitter as a means of promoting engagement and discussion in lectures.

\section{Methodology}

\subsection{Sample}

This study was conducted in the School of Education Studies at Dublin City University (DCU), Ireland. The study was carried out with a class of seventy eight $(n=78)$ first year undergraduate students, that had attended the module 'Social and Personal Development with Communication Skills' as part of their B.Sc. in Education and Training. The module was taught two hours a week during semester one and was a compulsory module for all participants on the degree. The author of this study was involved as the lecturer on this module, and interacted with students on a weekly basis.

\subsection{The module}

The module 'Social and Personal Development with Communication Skills' is a practical, skills based module designed to increase students' readiness and preparation for engaging fully with the University experience, and academic life. The overall aim is to provide students with the skills for independent learning and social interaction, while giving a foundation for developing critical thinking skills. The module also facilitates the beginning of reflective practice, recognition of learning strengths, and identification of communication skills necessary for working effectively in a range of learning situations. Module topics are 'goal setting', 'time management', 'learning styles and learning strengths', 'creativity and creative thinking', 'communication skills', 'conflict management', and 'stress management'.

\subsection{Description of process}

At the outset a Twitter account was set up using the name @es $125 \mathrm{dcu}$, a combination of the module code and University name. The decision to set up a separate account was taken to ensure students understood this to be an academic experiment and intrusions were not being made into their personal lives (Young, 2009b). Account details were populated with the lecturers name and University image as the profile picture. Finally tests were carried out using the web interface, SMS and Smartphone application to ensure all functionality was viable.

Students were then invited to participate in the study, with an emphasising being made, that the use of Twitter was entirely voluntary. The rationale for the study was then explained to the students and they were asked to set up a Twitter account and begin 'following' this. For this purpose, a demonstration was conducted, and students were directed to instructional videos on the University Learning Management System (LMS), where a range of videos were provided, along with documentation on using Twitter by SMS. Due to the content of the module, it was felt that ample opportunity for engagement, discussion and shared experience could be provided, thus presenting abundant scope to investigate the use of Twitter on these facets of communication.

To achieve this, an interactive and stimulating experience was created for students to participate in. Lectures contained a variety of materials and teaching methods. Each lecture contained a) PowerPoint presentations, b) minimum of one related video clip with pre and post questions, c) group work, d) questions and answers, and e) whole class discussion. Each of these areas was designed to solicit student opinions, feelings and experiences that could be discussed out loud or using Twitter via their mobile phone or laptop. In order to solicit responses from students, comments and opinions were asked for out loud and using the created Twitter account, as such; those students that had set up an account received these solicitations directly to their device. 
Twitter discussions were displayed to the group using the Twitter webpage, which remained open for the entirety of the class. For example, before each video clip was played, students were asked to consider a number of questions during viewing. In this scenario, after the video had finished, a whole class discussion was held where students spoke or 'tweeted' their thoughts on the video using the questions provided. During this discussion, the Twitter webpage was displayed on the projector screen; students' 'tweeted' comments were integrated into the conversation and related to other spoken comments. This process was followed through all of the different teaching strategies, with dialogue moving seamlessly from spoken comments to tweets. While this worked well, an element of technological comfort was required. Lectures involved multitasking between PowerPoint, Twitter and other applications such as YouTube and the University LMS system. This experiment was not for the faint hearted (Young, 2009a) and acceptance that things may go wrong was a prerequisite. As lectures progressed, different applications were used: PowerPoint was used to present materials while Twitter was opened during conversations. It is important to note that students could tweet at any time, and the alternating of applications was due to the restriction of having one projector screen.

\subsection{Instruments}

Data collection was carried out using a written questionnaire. Data gathered was a mixture of qualitative and quantitative information. Although certain personal information such as gender and age was elicited, questionnaires were kept anonymous. A series of open and closed questions were asked with the following three themes in mind; 1) Do students adopt Twitter as a means of engaging in lectures? What are the motivations for this adoption or lack of adoption? 2) What is the impact of Twitter on lecture engagement and discussion? 3) What are the emerging and/or possible uses of Twitter in University teaching?

In the first category, the adoption of Twitter, students were asked about their understanding of Twitter after taking part in the course. Had they set up an account for the purposes of this course and what, if any, were the motivations and difficulties associated with this set up? In the second category, students were asked a series of questions about the impact of Twitter on Lecture engagement and discussion. Through closed ended and accompanying open-ended questions, the impact Twitter had on classroom engagement and discussion was elicited, along with justification for these answers. For further elaboration, students were asked open-ended questions such as: What are the benefits of using Twitter in class? What are the drawbacks of using Twitter in class? What could have been done differently? And, did they find others 'tweeting' of benefit to classroom engagement and discussion? In the third category, data was gathered on the possible uses of Twitter in University teaching. Students were asked; how engagement could be improved using Twitter? How they would like to see Twitter used in class in future (including alternative uses)? And, how they would like to see Twitter used outside of class?

\subsection{Procedure}

Students attended the module over one semester as part of their overall study. The questionnaire was distributed at the end of semester, and students completed this anonymously. Out of the seventy eight $(n=78)$ students, sixty $(n=60)$ completed questionnaires were returned, giving a response rate of $77 \%$.

\subsection{Data Analysis}

The data collected for this research was analysed in two ways. Quantitative data (closed questions) were analysed using simple statistical analysis. In an effort to understand how students interpret the world (Maykut \& Morehouse 1994), qualitative data was analysed for patterns in the key words and phrases present in their responses. These were coded and grouped together as themes, 
student responses were assigned to one or more of these themes. These were then ranked according to the number of occurrences in the data to ascertain prominence.

\section{Findings and discussion}

Key themes and findings are now presented using quantitative data and extracts from qualitative responses in order to address each of the three categories on an individual basis, followed by overall conclusions and recommendations drawn from the study.

\subsection{Student adoption of Twitter}

In this section, the issues related to students' adoption of Twitter as a means of communication during lectures are analysed. Firstly, data on student usage of the platform will be presented, along with comments on possible reasons for this. Next, an examination of how participation in this study has affected students' understanding of the platform, and how this might affect their use of it as future educators, is conducted. Finally, the study examines the reasons some students adopted the platform, and others did not. Learning from this data may shed light on future possibilities for integration.

\subsubsection{Level of student engagement}

Given the voluntary nature of participation, initial enthusiasm to adopt Twitter for communication during lectures seemed high, with $56 \%(n=44)$ of students setting up an account within the first four weeks. This initial enthusiasm was also reflected in the number of tweets per class, especially during weeks two and three (Figure 1). This initial burst of involvement may be explained by students' desire to try something new. Note, week one consisted of an introduction to the module, and set up of Twitter procedures, and so had no opportunities to engage using the platform. Following this initial burst of involvement, a sharp drop off in tweets is evident in weeks four and five, possibly due to the waning of the novelty factor. However, participation using Twitter resurged somewhat after this period, and remained relatively constant for the remainder of the semester. This may be explained by a renewed push to display the Twitter page more often during class. Note, week seven was reading week, and weeks eleven and twelve consisted of practical work, again meaning students had no opportunity to engage using the platform.

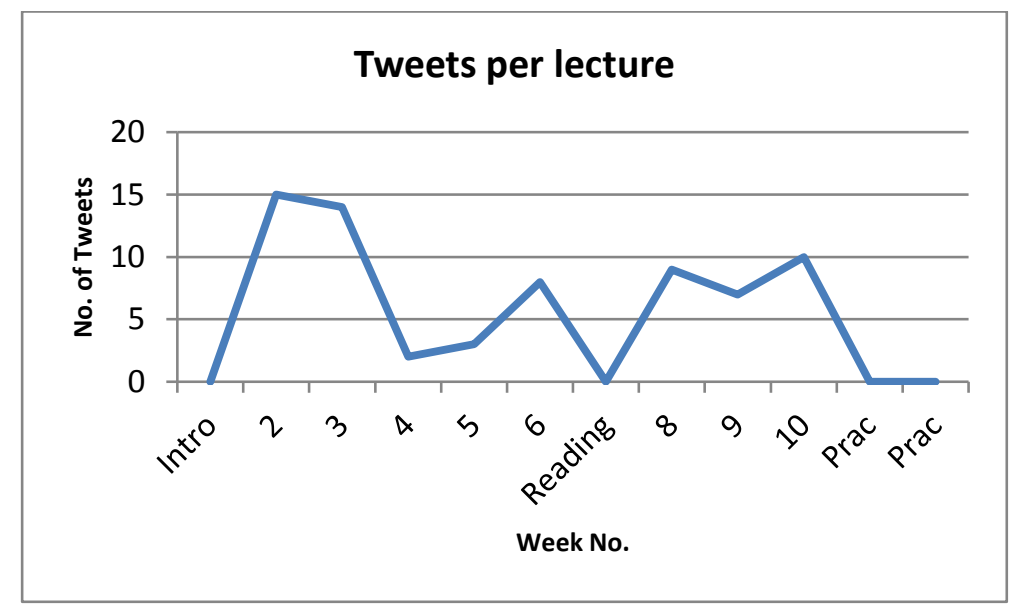

Figure 1 Tweets per lecture

Of those students that set up Twitter accounts, 36\% $(n=16)$ tried to engage in discussion using the platform, however the number of tweets varied greatly between students (Figure 2). Some students communicate quite regularly, while others participated infrequently. For example, student A sent a total of eighteen $(n=18)$ tweets, while student $K$ sent only one $(n=1)$. 


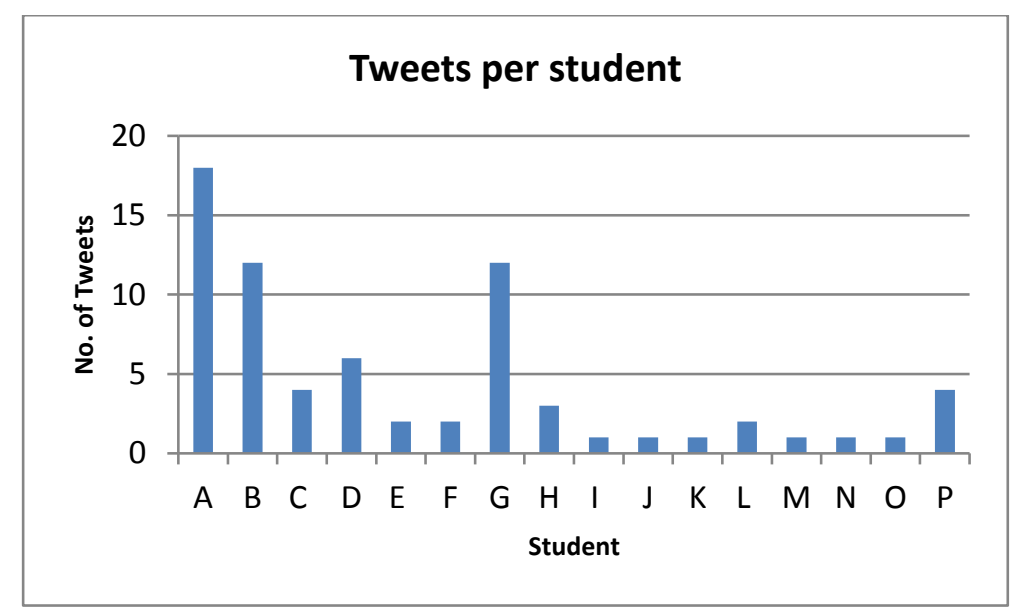

Figure 2 Tweets per student

\subsubsection{Understanding of the Twitter platform}

Regardless of levels of participation by students, evidence suggests that understanding of Twitter as a communications tool increased as a result of this study (Figure 3). Of the fifty $(n=50)$ responses to the question, 'how has your understanding of Twitter changed over the semester?' $38 \%(\mathrm{n}=19)$ indicated that their general understanding of Twitter as a communications tool, and how to use it, had improved. One student commented, 'I now realise you can interact with other people'. Significantly, a further $34 \%(n=17)$ of respondents indicated they had a better understanding of the potential uses for Twitter in educational settings. Students expressed an increased awareness of how Twitter can be used for 'learning', 'class discussion', and to increase engagement, 'instead of just entertainment'. The remaining $28 \%(n=14)$ of respondents signalled no change in their understanding of Twitter over the semester.

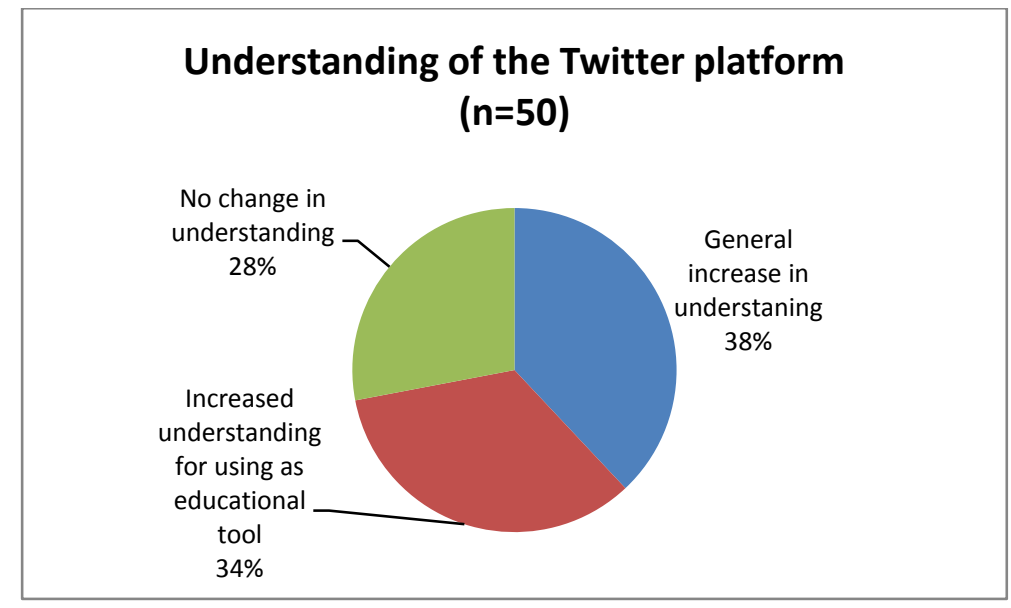

Figure 3 Understanding of the Twitter platform

\subsubsection{Reasons for Adoption and non-Adoption}

Now that the level of engagement using Twitter, and the understanding of the platform have been established, it is pertinent to understand the reasons why some students adopted the platform, while others did not. The follow sections give details on these areas, and may prove useful in identifying the success factors and areas for opportunity for future work.

\section{Reasons for adoption}

Students were asked to outline their motivations for adopting Twitter to communicate in class. All respondents indicated that the contribution of their ideas and experiences to the lecture, without fear or embarrassment, was pivotal. Students felt 'more comfortable' tweeting their opinions to a 
'large audience', and being involved in a 'less threatening' way. Those students that did not like 'speaking in front of large groups', felt Twitter helped them to 'engage in class discussion in a way that felt comfortable'. This ensured they 'never felt awkward', when contributing to class discussion. Others commented that 'putting hands up can be difficult', especially if asked a question 'they are not expecting'. Twitter gave them the opportunity to 'get their point across'. Some students who did not tweet later regretted 'not using it more, as being shy, they could have benefited' from engagement. One student summed this up well saying, 'I really like using Twitter to express my opinion in class, it was a brilliant idea. I'm not a big public speaker you see'.

\section{Reasons for non-adoption}

With adoption rates relatively low, it is important to understand the reasons why students did not engage using the platform. By analysing student responses, three main influencing factors were identified. These are a) Technological constraints (perceived and actual), b) Motivation to use the platform, and c) Facilitation during lectures.

\section{a) Technological constraints}

Of the twenty one ( $\mathrm{n}=21)$ completed responses in this category, the majority, $57 \%(\mathrm{n}=12)$, seem to have been discouraged by technical issues. Analysis of these responses reveal that, five $(n=5)$ were unable to participate, as they could not access the University wireless network. This appeared to cause frustration among students who said they 'could not connect to the internet most of the time', and they 'would have tweeted but the internet connection would never work in class'. A further four $(n=4)$ respondents attributed their lack of involvement to having no laptop or Smartphone in class. These students said they 'never brought a computer/Smartphone to class', and they 'didn't tweet' because they 'didn't have a Smartphone'. These students were either unaware of the ability to tweet via standard SMS technology, or were unwilling to incur the potential costs associated with sending SMS messages. Some mobile phone providers in Ireland offer Twitter SMS free, while others charge per SMS sent. The final three $(n=3)$ respondents indicated they had not set-up a Twitter account, or had difficulty doing so.

\section{b) Motivation to use the platform}

$33 \%(\mathrm{n}=7)$ of respondents stated they did not participate due to lack of interest, or feelings of insufficient need to use the platform. Five $(n=5)$ of these responses point to a lack of interest in Twitter, because 'class discussions usually covered opinions on various topics', and tweeting 'might distract them from listening'. The remaining two responses reveal these students felt no requirement to tweet, saying they 'don't mind having something to say out loud', and they 'could say what they want to say quicker than tweeting'. One student espoused a lack of value in communicating in this manner during lectures, saying, 'I prefer to actually communicate; Twitter defeats the purpose of classroom engagement'.

\section{c) Facilitation during lectures}

From time-to-time students were asked to elaborate on their tweets. To achieve this, students were called upon to expand on their points, in front of the group. This form of facilitation seems to have deterred the final $10 \%(\mathrm{n}=2)$ of respondents from participating. These students disliked the fact that they still had to talk out loud, and were uncomfortable 'being singled out in front of the class'. We can see from the above data that full adoption of Twitter was certainly not achieved, and was in fact used by a relatively small percentage of the class to engage in discussion. However, those that used the platform valued the ability to contribute their opinions, ideas and experiences. The voluntary nature of participation illustrates that these students appreciate a platform to speak out in a less threatening way. Also evident is an increased understanding of Twitter, and its potential uses within education. This may provide students with alternative tools to use in the future. While technology enabled this experience for some, it hampered it for others. The majority of those that 
did not participate were held back by technical issues. Data suggests that providing students with clearer instructions and assistance on accessing the University wireless network, using Twitter by SMS, and account set-up, may increase participation using the platform. Approximately one third of respondents indicated a lack of interest or need for Twitter, this raises important questions on the integration of Twitter in the lecture setting. The data suggests that a careful balance must be achieved to ensure Twitter is only used to enhance the contributions of those who ordinarily feel shy or embarrassed. However, the platform should not interrupt or hinder those who prefer traditional engagement. Finally, it can be suggested that those who choose to participate using Twitter should be allowed to do so in a passive way, and should not be called upon to elaborate out loud.

\subsection{Affect on engagement and discussion}

With the adoption of Twitter established, understanding the impact on lecture engagement and discussion for the entire group is critical. To achieve this, interactions that took place using Twitter are displayed. Sample interactions are illustrated, along with comments on the possible implications for future use. Second, the impact on engagement and discussion is presented, with comments on potential impact. Finally, suggestions and feedback from students, on how engagement using the platform might be increased, are provided.

\subsubsection{Interactions using Twitter}

By analysing student contributions that took place via Twitter during class, a variety of interaction types are revealed (Figure 4). These can be categorised as, a) Student responses to lecture questions, b) Shared experiences, opinions, and concerns, c) Comments on lecture content, and d) Direct questions.
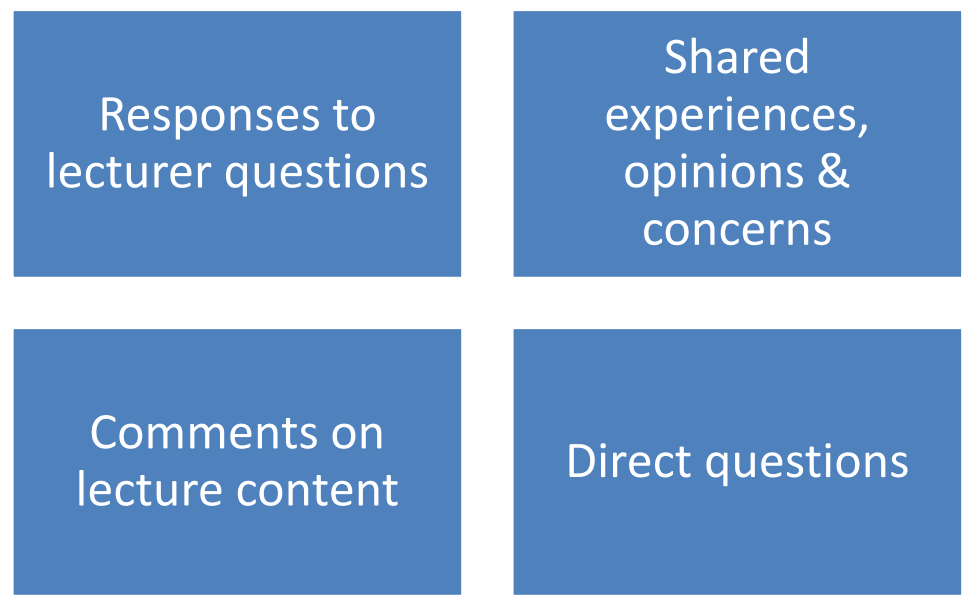

Figure 4 Interaction types

\section{a) Student responses to questions}

In some instances, Twitter was used by students to directly answer questions posed by the lecturer. For example, during a lecture on communication skills, the question was posed, 'What is communication Skills?' Student B responded, 'the ability to impart or receive information be it verbally or non-verbally'. Student G responded, 'communication skills help us carry out conversations effectively. Some skills are talking, eye contact and body language'. During another lecture on conflict management the question was posed, 'Why does conflict happen?' Student A responded, 'group conflict happens when people clash heads on different topics or clash of personality'. Student C responded, 'it is a battle to be the dominant person or leader of a group'. The variety of language and expression used during the exchanges outlined here, suggests some value in providing students with the opportunity for free text responses as opposed to closed 
questions. Students who participated appear willing to open up and engage with the topic in a meaningful way.

\section{b) Shared experiences, opinions and concerns}

Also evident from analysing students' tweets is a willingness to share opinions, concerns, and experiences with the lecturer and their peers. For example, during a lecture on goal setting, students began sharing their personal goals with the group. Student G shared that one of her goals was to 'actually understand the Harvard system', while student I said one of his goals was 'making the DCU soccer team'. During the same conversation on goals, the lecture moved to balancing the different areas of one's life. During this discussion, student B commented, 'no balance yet, still adding University to what I do at the moment'. Student A commented, 'currently struggling to get the correct balance between sport and college'. We see here that students using Twitter are engaging in personal interactions with the lecturer and their peers, and seem willing to share opinions, concerns and experiences with the wider group. Twitter appears to afford these students with the opportunity share in this way.

\section{c) Comments on lecture content}

Students also began using Twitter to contribute to the lecture by commenting on, and adding to lecture content. This was particularly evident when viewing videos. Students were given discussion points to look out for during video segments, and individuals sent tweets during the play through, commenting on the content. For example, during a video on communication skills, Student A commented that 'he [the speaker] uses humour and uses visual aspects to grab the attention of the audience', later following up with, 'the important thing is confidence along with knowing the information being delivered'. While video segments provided a perfect opportunity for this kind of interaction, these comments on lecture content were not limited to this time, and occurred during most teaching scenarios. For example, during our lecture on stress management, student B tweeted, 'talk to family and friends. A problem shared is a problem halved. Friends also make good sounding boards'. Similarly during our goal setting lecture, student H commented 'people can be inspirational. But if you have watched someone fail then you will make sure you don't make their mistakes'. Student D shared related information, tweeting a link to a website along with the text 'a website I often use for my goal setting'. These tweets show that Twitter was used by students to share their input, outside of fixed question and answer time. It may be suggested that these comments and ideas helped students to link lecture content to their own experiences, adding to the group's interpretation of the content.

\section{d) Direct questions}

Outside of normal question time, some students used Twitter to ask direct questions to the lecturer, while other activities were in progress. These could then be addressed during conversation, when the Twitter feed was open. For example student $\mathrm{G}$ asked, 'can we use quotes in our video learning $\log$ ? If we reference who said it?' This same student also asked on another occasion, 'do your two essay topics have to link or relate to each other? Can they be different?' Student P asked, in relation to goal setting, 'what if your goals are a bit vague?' These tweets show that Twitter is a possible tool for students to direct questions to the lecturer and the wider group, possibly allowing these students to gain clarification on issues they may otherwise have been reluctant to ask.

By analysing the interactions outlined above, it is clear that Twitter was used, by those that participated, for a variety of purposes within lectures. While it is difficult to extrapolate past this small user group, the level of engagement, discourse, and openness displayed by students that did tweet, suggest that the platform is feasible for a number of interactions; such as questioning, connecting with other students, sharing thoughts, experiences and concerns, and engaging fully with the lecturer. 


\subsubsection{Impact on engagement and discussion}

Following examination of the interactions that took place via Twitter, student responses to the impact of Twitter on lecture engagement and discussion were analysed. Responses, which were drawn from the entire group (not simply those that used Twitter), indicated that the overwhelming majority of students felt Twitter impacted positively on engagement and discussion. By breaking down perceived communication barriers the dynamics of conversation were altered whereby students could participate in their own time and 'from every corner of the room', thus reducing the need for rigid question and answer time. This more 'relaxed' and 'fun' atmosphere also afforded the more 'shy and timid' members of the group the opportunity to contribute, leading to an 'exciting mix' of tweets and spoken comments, combined to produce a rich debate and 'intense conversation'. Interestingly Twitter did not lend itself to apathetic contributions. In fact the need to be concise ( $\leq 140$ characters), and present to an 'audience', encouraged students to process ideas fully, 'cut the waffle' and link to the subject matter in a worthwhile way. Through this process of group learning, student understanding of topics increased by taking the conversation in 'new but related directions', while simultaneously creating a sense of awareness and community among the group. Students felt more comfortable as they 'got to know each other' and there was a palpable feeling of a community developing.

In addition to student feedback outlined above, researcher observations paint a similar picture of Twitter's impact on the dynamics of engagement and discussion. An increased volume of student contributions were noticed, with these offerings strengthening the quality of engagement by creating a variety of inputs for debate and discussion. This in turn led to more rewarding dialogue in class, where information was woven between tweets and spoken comments to create a more complete picture of student perceptions. It was also noted that the development of a sense of community extended past the boundaries of the student population, recognising that through shared experience and Twitter profiles, an increased awareness of student needs and progress was developed.

\subsubsection{Increasing Engagement using Twitter}

Students felt that for Twitter to have a real impact, numbers using the platform must increase, commenting that the same students used it every week. This is also reflected in the analysis of tweets shown earlier (Figures $1 \& 2$ ). Responses $(n=59)$ indicate a number of areas that may contribute to increased participation by students. These are a) Technology, b) Facilitation of engagement, and c) Encouraging use.

$37 \%$ of responses $(n=22)$ again related to the perceived technological constraints in using Twitter in lectures. Students commented that 'spending more time on the set up in class' or giving a more in-depth 'tutorial on the basics' of using Twitter, would increase their involvement. 34\% of respondents $(n=20)$ suggest that modifications to the way in which engagement and discussion are facilitated, could improve uptake and use of the platform. Of these, five $(n=5)$ respondents simply suggested refreshing the Twitter feed more often and 'switching to it more often'. Four $(n=4)$ suggested dividing the class into groups for discussions, so that group consensus could be tweeted out, and those without Twitter could 'get involved'. Two $(n=2)$ respondents discouraged the singling out or 'putting on the spot' of students who send a tweet. The remaining nine $(n=9)$ responses contained a variety of suggestions to increase use e.g. 'activities and quizzes', 'fun exercises' and 'allocated Twitter time'. $29 \%(\mathrm{n}=17)$ of respondents outlined a variety of potential strategies that might encourage them to use the platform. Six $(n=6)$ suggested that the use of Twitter should be compulsory with 'at least one Tweet per class'. Seven $(n=7)$ simply suggested that its use should be 'encouraged more', while four $(n=4)$ said that using Twitter could form part of the module assignment. Student responses here indicate that while uptake of the platform was low, the integration of Twitter into a variety of lecture activities may increase students' adoption 
of the platform as a means of engagement. Responses here indicate that students appreciate the potential of providing a means of real time communication within lectures.

\subsection{Emerging/possible uses of Twitter}

When asked what the emerging or possible uses of Twitter might be outside the classroom, students $(n=28)$ indicated a variety of ways Twitter could be used to aid discussion, and support their studies. These can be categorised into a) Discussion tool outside class time, b) Formative assessment tool, and c) Source of additional information.

$38 \%$ of respondents $(n=11)$ indicated that they would like to see Twitter used 'outside of the classroom to continue discussions', in doing so, students could share their 'ideas and opinions' throughout the week and lectures wouldn't 'just last two hours'. This continuation of learning could also support students' collaboration by tweeting 'a question or problem', where students could 'get in touch with their classmates' and 'help each other out'. Evidence of this began emerging, with students contributing comments outside class time. For example, Student K tweeted between classes, suggestions on relaxation techniques on our topic of stress management, saying 'do something you enjoy doing during a stressful time'. Others began sharing more than thoughts and experiences, posting links to relevant articles and websites for others to view. For example, Student D tweeted between classes 'check out Desmond Morris studies on body language'. $28 \%$ of respondents $(n=8)$ indicated they would like to see Twitter used as a formative assessment tool, where lecturers can post 'questions about the module' or 'mini tests' to check understanding and prepare for projects or examinations. Students felt that this form of interaction would give them 'valuable information' and 'short, concise feedback'. Finally, $31 \%$ of respondents $(n=9)$ indicated they would like to see Twitter used as an additional source of information and contact with their lecturer. Students would like to be able to 'ask their lecturer questions' and make 'comments on module content', outside of class time. They would also like lecturers to begin sharing additional content, for example, 'posting readings and videos', 'relevant links', 'assignments', and 'study tips'. This seems to concur with Carnevale's (2006) synopsis that email is for old people, and students are looking for innovative ways of communicating with faculty and each other. While this poses many challenges for lecturers and faculty, it may provide students with the ongoing support and encouragement they need to stay engaged with content between lectures.

\section{Conclusions \& Recommendations}

The purpose of this study was to examine how Twitter could be used for lecture engagement and discussion by University students, and in particular, those who may traditionally by shy and intimidated in lecture settings. Findings indicate that, while uptake of the platform was quite low, those students that did engage did so to contribute to lectures in a less intimidating way. It can be suggested from this that in its current form, Twitter could be as an optional tool to encourage engagement from everyone within the group. In order to provide this opportunity for as many students as possible, work needs to be done to ensure the technology is both working and fully understood by students. It is apparent from this study that seemingly insignificant issues for the 'digital generation' (Prensky, 2009) such as: connecting to the University wireless network, and setting up a Twitter account, can still cause frustration and exclude some students from participating. Valuable lessons were also learned in relation to facilitation skills when using Twitter in lectures. It emerged that students who used Twitter, appeared to do so to engage in a less threatening way. For this reason, solicitations for further vocal engagement were potentially counterproductive, and actually discouraged others from using the platform. It would seem that there is a delicate balance between encouraging students to engage fully in lectures, and managing this participation in such a way that does not intimidate them by putting them in the spot-light. The variety of interactions displayed using the platform suggests that Twitter can positively impact on 
a variety of lecture situations, such as; questions and answers, sharing of thoughts, feelings, ideas and concerns, elaborating and commenting on lecture content, and clarification of student issues. What is most encouraging in this respect is that the 140 character limit imposed by Twitter, did not seem to hinder student engagement and in fact encouraged students to process the information, and present it back to the group in a thoughtful and meaningful way. While recognising that up-take of the platform was low, the whole group, including those that did not use the platform for various reasons, found that the availability of Twitter for interaction had a positive impact on class engagement. The presence of Twitter seemed to change the atmosphere in the lecture room, where all students could sense a feeling of inclusion. Contributions were unrestricted, and the relaxed atmosphere that was created encouraged everyone to share their views. This created a rich mix of ideas that could be combined to create a more complete picture of class perceptions and feelings. Most importantly, the contributions via Twitter did not have a negative impact on those that did not use the platform. In order to broaden the adoption of Twitter, a more dynamic and integrated approach to using Twitter in the lecture room is needed. Students suggestion of 'Twitter time' and its integration into activities and games, suggests that a hybrid of the approaches of ARS and Twitter described earlier might be useful. Marrying the free-flowing nature of Twitter, which allows conversation and discussion, with all-class interaction and quizzes of ARS, may provide an ideal balance of interaction opportunities and motivation for all those within the class. Finally, the potential to engage students outside of lectures by providing support, facilitating peer support, and providing questions to provoke thought throughout the week, is an interesting prospect. While this kind of activity could place extra strain on lecturers and faculty, it may result in deeper and more satisfying learning experiences for students. This area requires further research to establish its viability and impact on student learning.

\section{Limitations}

This study has a number of limitations that must be mentioned to contextualise the findings and conclusions above. Firstly, the sample size from which the data were drawn was very limited. This is in part due to the number of students taking part in the course. However, data obtained in relation to students interactions using Twitter and its impact on engagement and discussion were particularly low in number. This can be attributed to the voluntary nature of participation and perceived need to use the platform as outlined in earlier sections. This does limit the potential impact of findings and conclusions. The intent of this study was to capture the impact and adoption of Twitter, when presented to students in a voluntary manner; however a larger scale study is needed to further develop these areas. Secondly, the data obtained were gathered using a single questionnaire administered at the end of one academic semester. A more strategic, long term evaluation may yield more robust conclusions. Finally, due to the relatively recent emergence of Twitter, literature sourced for the study was scarce and so was combined with literature on other interactive technologies. It is possible that as research in this area increases, alternative themes may emerge that warrant study.

\section{References}

Abate, L.E., Gomes, A., and Linton, D. (2011). Engaging Students in Active Learning: Use of a Blog and Audience Response System. Medical Reference Services Quarterly, 30(1), 12-18. Taylor and Francis Group.

Bates, S.P., Howie, K., and Murhpy, A. St. J. (2006). The use of electronic voting systems in large group lectures: challenges and opportunities. New Directions in the Teaching of Physical

Sciences, 2, 1- 8

Beldarrain, Y. (2007). Distance Education Trends: Integrating new technologies to foster student interaction and collaboration. Distance Education, 27(2), 139 - 153 
Bligh, D.A. (1998). What's the use of lectures? Intellect books

Bruner, J.P., (1967). On knowing: essays for the left hand. Mass: Harvard University Press

Carnevale, D. (2006). Email is for old people. Chronicle of Higher Education.

http://chronicle.com/article/E-Mail-is-for-Old-People/4169. Accessed 08 February 2012

Chickering, A., and Ehrmann, S.E. (1996). Implementing the seven principles: Technology as lever. American Association for Higher Education, 3 - 6

Creswell, J. (2003). Research Design. 2nd edition. London: Sage publications.

Crotty, Y. (2011). Through the enlightened eye and I, am I bringing creativity and visual literacy into Higher Level Education? Educational Journal of Living Theories, 4(1), 1 - 36

Crouch, C.H., and Mazur, E. (2001). Peer Instruction: Ten years of experience and results. American Association of Physics Teachers, 69(9), 970 - 977

Draper, S.W., and Brown, M.I. (2004). Increasing interactivity in lectures using and electronic voting system. Journal of computer assisted learning, 20, 81 - 94. Blackwell publishing limited.

Duncan, D. (2005). Clickers in the Classroom: How to Enhance Science Teaching Using Classroom Response Systems. San Francisco: Pearson Education.

Dunlap, J.C. and Lowenthal, P.R. (2009). Tweeting the night away: Using Twitter to enhance social presence. Journal of Information Systems Education, 20(2).

Ebner, M., Lienhardt, C., Rohs, M., Meyer, I. (2010). Microblogs in Higher Education - A chance to facilitate informal and process-oriented learning? Computers \& Education, 55, 92 - 100. Elsevier.

Educause (2007). 7 things you should know about Twitter. ELI 7 Things you should know. http://net.educause.edu/ir/library/pdf/ELI7027.pdf. Accessed 06 February 2012.

Farren, M. (2008). eLearning and Action Research as Transformative Practice. Innovate Journal of Online Education, 5(1).

Feden, P.D. (1994). About instruction: Powerful new strategies worth knowing. Educational Horizons, 73, $18-24$.

Gusbers, V., Johnston, J., Hancock, D. and Denyer, G. (2001). Why do Students still Bother Coming to Lectures, When Everything is Available Online? International Journal of Innovation in Science and Mathematics Education, 19(2), 20 - 36.

Hesmondhalgh, P. (2011). 10 Reasons Teachers should give Twitter a go. The creative education blog. http://www.creativeeducation.co.uk/blog/index.php/2011/09/10-reasons-to-tweet/. Accessed 08 February 2012.

Junco, R., Heibergert, G. and Loken, E. (2011). The effect of Twitter on college student engagement and grades. Journal of Computer Assisted Learning, 27, 119 - 132.

Laurillard, D. (2002). Rethinking university teaching: A conversational framework for the effective use of learning technologies, 2. London: RoutledgeFalmer.

Maykut, P. and Morehouse, R. (1994). Beginning Qualitiative Research: A philolsophical and practical guide. London. RoutledgeFalmer. 
Meyer, K. (2002). Quality in distance education: Focus on online learning. ASHE-ERIC Higher Education Report, 29(4).

McElroy, J. and Blount, Y. (2006). You, me and iLecture. Proceedings of the Australasian Society for Computers in Learning in Tertiary Education (ASCILITE) Conference (pp. 549-558). Sydney Australia, Dec 3-6.

http://www.ascilite.org.au/conferences/sydney06/proceeding/pdf papers/p87.pdf. Accessed 11 December 2012

Moore, M.G. (1989). Three types of interaction. American Journal of Distance Education, 3, 1 - 7.

Morales, L. (2011). Can the Use of Clickers of Continuous Assessment Motivate Critical Thinking? A case study based on Corporate Finance students. Higher Learning Research Communications, 1, $33-42$.

Moss, K. and Crowley, M. (2010). Effective learning in science: The use of personal response systems with a wide range of audiences. Computers \& Education, 56, 36 - 43. Elsevier.

Presnsky, M. (2009). H. sapiens: From digital immigrants and digital natives to digital wisdom. Innovate, 5(3). Fischler School of Education and Human Services. Nova Southeastern University.

Rankin, M. (2009). The Twitter Experiment at UT Dallas.

http://www.utdallas.edu/ mrankin/usweb/twitterconclusions.htm. Accessed 08 February 2012.

Simpson, V., and Oliver, M. (2007). Electronic voting systems for lectures then and now: $A$ comparison of research and practice. Australian Journal of Educational Technology, 23(2), 187 208.

Steinert, Y., and Snell, L.S. (1999). Interactive lecturing: Strategies for increasing participation in large group presentations. Medical Teacher, 21, $37-42$.

Tamim, R.M., Bernard, R.M., Borokhovski, E., Abrami, P.C., Schmid, R.F. (2011). What forty years of research says about the impact of technology on learning: A second-order meta-analysis and validation study. Review of Educational Research, 81(1), 4-28.

Thompson, C. (2007). How Twitter Creates a Social Sixth Sense. Wired Magazine, 15(7).

Volery, T. (2001). Online education: An exploration study into the success factors. Journal of Educational Computing Research, 24(1), 77 - 92.

Von Konsky, B. R., Ivins, J. and Gribble, S.J. (2009). Lecture attendance and web based lecture technologies: A comparison of student perceptions and usage patterns. Australian Journal of Educational Technology, 25(4), 581 - 595.

Vygotsky, L.S. (1978). Mind and society: The development of higher mental processes. Mass: Harvard University Press.

Young, J. (2009a). Teaching With Twitter: Not for the Faint of Heart.

http://chronicle.com/article/Teaching-With-Twitter-Not-for/49230/. Accessed 08 February 2012.

Young, J (2009b). When Professors Create Social Networks for Classes, Some Students See a 'Creepy Treehouse'. http://chronicle.com/blogs/wiredcampus/when-professors-create-socialnetworks-for-classes-some-students-see-a-creepy-treehouse/4176. Accessed 08 February 2012. 